\title{
3 \\ Evolving Expectations for Teaching in Higher Education in Canada
}

Gary A. Hunt

Thompson Rivers University

Alan Wright
University of Windsor

George Gordon

University of Strathclyde, Scotland

Although many Canadian universities offer graduate level training or certificates on teaching in higher education, there is no national framework of expectations or provision for national certifcation of post-secondary teachers. There are models of post-secondary teaching expectations in the United Kingdom and in elementary and secondary systems in both the US and Canada. In addition, many US universities have competency-based graduate teaching assistant programs. The province of Ontario has adopted a mandatory framework of learning expectations for Baccalaureate and graduate degrees for all publicly funded universities. The question we address in this essay is: Has our teacher training practice evolved to the point where we should look ahead to consider formalizing expectations of effective post-secondary teaching practices through a national framework?

In our view, there is now sufficient interest within the Society for Teaching and Learning Higher Education (STLHE) to establish a working group that would initiate a national consultation to discuss the process and structure for formulating an enabling framework.

\section{Introduction}

ramework structures describing expectations for

teaching are well established in North America and in the United Kingdom (UK). Examples include core professional competencies for K-12 teachers in 
Quebec (Gouvernement du Québec, 2001); core propositions for $\mathrm{K}-12$ teachers in the US (National Board for Professional Teaching Standards, 2008); two schemes for post-secondary teachers in the UK; Staff and Educational Development AssociationProfessional Development Framework (SEDA-PDF, 2005); and the Higher Education Academy (HEA, 2007).

Canada has no national framework of expectations in higher education. Many Canadian universities offer graduate level training or certificates on teaching in higher education. Each institution tailors its training curriculum to meet the needs of its students and faculty. A national scheme formalizing our expectations for post-secondary teachers would have numerous benefits. These include having a nationally adopted reference framework for educational developers; transferability of certification across institutions; demonstrating to students and other stakeholders that we have an effective, professional teacher training network which supports student engagement and learning; and raising the professional profile of teaching and learning in higher education. Such a framework would permit institutions and programmes to develop unique approaches to teacher training, but within a framework of accepted educational outcomes. Non-regulatory, professionally led approaches to the development of such a framework appear to offer attractive and supportive opportunities for discussion.

\section{Teacher Training and Development Curricula in Canada}

Our survey of teacher training courses and programmes offered at 12 Canadian universities indicates that there is a core set of curriculum topics that are considered to be important across these institutions. This suggests that a framework of expectations for post-secondary teachers should include these subjects. Curriculum topics fall into three areas: core knowledge, classroom teaching skills, and evaluation of teaching practices.

The important core knowledge expected of teachers includes information about institutional or- ganization, learning theory and educational philosophy, curriculum development and course design, and learning environments. Adequate discipline-specific content knowledge forms the basis of all teaching strategies.

Knowledge about institutions includes such things as administrative structure and policy, professionalism and ethics, the role of teaching in the institutional mission, and the obligations and opportunities for developing as a teacher at individual institutions. Learning theory and educational philosophy covers teaching and learning theory, how adults learn, and the philosophy and goals of higher education. Curriculum development and course design deals with aligning course goals, teaching methods, and assessment; writing learning objectives; and assessment of student learning (test design, rubrics, and evaluating a variety of student work). Creating positive learning environments encompasses student motivation and success, mentoring, course management software, and recognition of diversity in learning styles, ability, gender, and ethnic background.

Essential skills in classroom teaching are a fundamental component of teacher training. Most often these are taught by introducing a variety of instructional strategies and then practicing them in a classroom environment such as instructional skills workshops or in practicum experiences. It is common for programmes to consider a wide range of instructional strategies including working one-on-one with students, facilitating classroom discussion, effective lecturing, and a host of collaborative learning tactics such as problem-based learning, team-based learning, and active learning activities. In addition, teaching for particular sub-groups is often addressed. These may be teaching large classes, strategies for specific disciplines, distance and online education, and teaching first-year students.

How teachers evaluate their practice comprises another sphere of teacher training. This is generally composed of knowledge about teaching as a reflective practice, the elements of a teaching dossier, and writing useful learning journals. Also included here is using feedback from students and peers in formative evaluation. 


\section{The Ontario Framework of Graduate Expectations}

The Province of Ontario has adopted framework guidelines which elaborate the knowledge and skills expected of students at four levels: bachelor's degree, bachelor's degree: honours, master's degree, and doctoral degree. The University Undergraduate Degree Level Expectations were prepared by the Ontario Council of Academic Vice Presidents (OCAV, 2007) and the Guidelines for University Graduate Degree Level Expectations were prepared by the Ontario Council on Graduate Studies (OCGS, 2005). The purpose of these framework guidelines is to explicitly state the expectations of performance by students. It is presumed that these will be valuable in a number of ways including credit transfer, professional qualification, and the evaluation of instruction and programme accreditation.

To detail one example, the Graduate Degree Level Expectations define six general expectations: depth and breadth of knowledge, research and scholarship, level of application of knowledge, professional capacity/autonomy, level of communications skills, and awareness of limits of knowledge. Within each expectation, examples of outcomes that could be used to meet the expectation are stated. For example, at the doctoral level, depth and breadth of knowledge is demonstrated by evidence that students have a thorough understanding of a substantial body of knowledge in their academic discipline or area of professional practice.

We use the Ontario framework guidelines to illustrate the important point that an effective framework structure, while explicitly stating required expectations, allows a high degree of flexibility in how the expectations can be met. Thus, for the example, there are many different ways in which a "thorough understanding of a substantial body of knowledge" can be demonstrated. It is likely the evidence for demonstrating understanding of knowledge could be different in arts programmes compared to science or professional programmes, for example. Therefore, the advantage of the expectations framework is that individual institutions and programmes have wide latitude to develop a variety of strategies to meet each expectation.

\section{The UK Professional Standards Framework}

The UK Professional Standards Framework is detailed in the document, Teaching and Supporting Learning in Higher Education (HEA, 2006). The idea of such a Framework was featured in the UK Government White Paper, The Future of Higher Education (UK Department for Education and Skills, 2003). Although this document addressed only the English higher education sector, all of the relevant funding bodies subscribed to the Framework, as did Universities UK and SCOP (the Standing Conference of Principals).

Development of the Framework entailed national consultations with key stakeholders on possible proposals and structures. That task was given to the Higher Education Academy which was charged by the key stakeholders (the Funding Councils and the relevant sector-bodies for universities and colleges) with consulting and producing a Framework.

The debate was also influenced by the existence of the relevant Sector Skills Council. These are employer-led bodies that set standards for training, and development for each major employment sector.

Thus, the HEA had the tricky task of simultaneously satisfying several different audiences, e.g., academics, students, employing institutions, staff unions, funding councils, Government, and the Sector Skills Council. In those circumstances, it is perhaps not surprising that the task took some time, and the Framework was finally published in 2006 (HEA, 2006).

The stated aims of the Framework include supporting professional development of staff who are engaged in teaching and supporting learning, fostering professional approaches in support of student learning and providing a means of demonstrating that professionalism to students and other stakeholders, and aiding consistency in the quality of the student learning experience, while encouraging creativity and innovation. 
The Framework is based upon six areas of activity, six aspects of core knowledge, and five professional values. Recognising that individuals engaged in teaching and learning support span a range of experiences and stages of development, the Framework developed three standards, respectively addressing:

- relatively inexperienced staff (GTAs or new staff) or those with limited teaching and learning support roles;

- staff with more substantive roles; and

- experienced staff who exercise mentoring and leadership development roles.

The Framework provides broad descriptors for each standard but expects individual institutions to determine the detailed criteria.

The standards also allow for individuals to seek professional recognition with designation as Associate, Fellow, or Senior Fellow. Adjustments have been made by the HEA so that the Academy's Professional Recognition Scheme nests neatly with the Professional Standards Framework. The Recognition Scheme contains various routes to recognition. These have progressively developed over several years, but the principal paths are either via an accredited programme, i.e., an institutional developmental programme that is accredited by the HEA, or through an assessed individual developmental portfolio. The intention of the Recognition Scheme is that each designation should be comprehensively portable. Anecdotal reports indicate this is not yet recognized throughout the system, but this may be symptomatic of the young Framework. Institutions are free to operate within the framework without necessarily expecting individuals to formally seek a particular category of recognition from the HEA.

The six areas of activity outlined in the Framework are:

- design and plan learning activities;

- teach and/or support student learning;

- assess and give feedback to learners;

- develop effective learning and student sup- port environments;

- integrate scholarship, research, and professional activities with teaching and supporting learning; and

- evaluate practice and pursue continuing professional development.

The six dimensions of core knowledge are knowledge and understanding of:

- the subject material;

- appropriate methods of teaching and learning;

- how students learn (generally and subjectspecific);

- use of appropriate learning technologies;

- methods of evaluating effectiveness of learning; and

- implications of quality assurance and enhancement.

The four professional values are:

- respect for individual learners;

- commitment to incorporating the process and outcomes of relevant research, scholarship and/or professional practice;

- commitment to widening participation, diversity, and equality;

- commitment to continuing professional development, reflection, and evaluation.

Two final comments are appropriate in relation to the UK situation. First, the consultation clearly demonstrated that institutions did not, on balance, favour a competency-based scheme (specific criteria needed to meet each topic area) and they were circumspect about potential interference with their right to select and appoint staff.

Second, there is another system of accreditation of professional development operated by the Staff and Educational Development Association (SEDA-PDF, 2005). Institutions, if they wished, could 
observe the Framework and seek SEDA recognition. It is likely that, at least for a period, two schemes will continue to operate. Much depends on how institutions implement, interpret, and translate into practice the Framework, and also on how they view the HEA Recognition Scheme.

\section{Feedback from Workshop Participants}

Many participants in our workshops in 2006 and 2007 (Hunt, Wright, \& Gordon, 2007) have indicated support for developing a national framework of expectations for post-secondary teachers. Potential benefits they have mentioned include providing a reference framework for:

- continuing professional development of all faculty;

- teacher training for $\mathrm{PhD}$ students, as well as new and experienced faculty;

- formative evaluation of teaching;

- aligning teacher training curriculum outcomes;

- professional standards that align more closely with other professions such as doctors and engineers;

- hiring, promotion, and tenure;

- demonstrating accountability to students and other stakeholders;

- national recognition (accreditation) of certificate programmes; and

- national certification of individual teachers.

Workshop participants have also expressed concerns about developing a national framework of expectations. These include the need for resources within a national body to administer the programme, ensuring that the programme is used to support effective teaching and not as a tool for discipline, ensuring there is wide flexibility in ways to meet the criteria, and making certain that the framework is developed through wide consultation of stakeholders.
Through these workshops we have also learned about outcomes developed for college teachers. For example, Fanshawe College (London, Ontario) has launched a new certificate program in college teaching, the Ontario Graduate Certificate in College Teaching (R. Rodgers, personal communication, July 9, 2007). The outcomes for this programme were developed in collaboration with other postsecondary institutions and may become a model for college teaching across the Province. Twelve learning outcomes are listed for the programme:

1 Design and deliver learning activities/experiences that utilize theories of college education and adult learning.

2 Design effective lessons, courses, and programmes of learning by utilizing effective curriculum development tools and strategies.

3 Create a climate for learning through a variety of classroom management strategies.

4 Facilitate student learning by utilizing a broad variety of instructional methods, tools, and approaches.

5 Integrate a philosophy of student success into the design and delivery of learning activities.

6 Design and deliver student learning activities that anticipate and respond to the diversity of student learning needs.

7 Design formative and summative evaluation techniques and tools that appropriately assess student achievement of learning outcomes.

8 Develop a teaching philosophy that reflects an understanding of college culture and the practice of the professional educator.

9 Develop documents that provide evidence of a commitment to reflective practice.

10 Create plans that recognize the need for ongoing professional development.

11 Analyze educational leadership issues inherent in the college context.

12 Successfully complete a supervised practicum experience that integrates the knowledge and skills acquired throughout the programme. 


\section{Summary and Conclusions}

Many Canadian institutions of higher education offer certificates in teaching in higher education. These offer developmental opportunities to faculty and often graduate assistants. They also enable institutions to actively support the preparation of faculty for their roles in teaching and learning. Further, such programmes can constitute a valuable component in assessing the performance of developing teachers. In the college sector in Canada, there is an overarching framework under development. In the UK, a Professional Standards framework has been defined and is well established.

Feedback from past workshops at STLHE Conferences in 2006 and 2007 strongly suggested that there is a substantial interest in initiating steps to develop an appropriate Canadian framework. Among the potential benefits would be providing a point of reference for training of current and future faculty, and demonstrating assurance of quality standards to higher education stakeholders. In addition, such a scheme could be the basis of national accreditation of teacher training programmes as well as individual recognition through inter-institutionally portable certification (teaching designations).

The tenor of Canadian discussions echoes that in the UK with a predisposition toward a flexible framework based on key values and dimensions, but with the details left to institutions to determine.

In this paper, we have briefly recounted the basic features of the UK Professional Standards Framework and outlined the learning outcomes of the Ontario Graduate Certificate in College Teaching as examples of framework structures that may be useful reference points in developing a Canadian national plan.

Has our teacher training practice evolved to the point where we should consider formalizing expectations of effective post-secondary teaching practices through a national plan? In our view, there is now sufficient interest within STLHE to establish a working group that would initiate a national consultation to discuss the process and structure for formulating an enabling framework. In so doing, STLHE could draw encouragement from the pioneering efforts in the 1990's of the Staff and Educational Development Association (SEDA) as well as subsequent work by other bodies and in other countries.

\section{References}

Gouvernement du Québec. (2001). Teacher training: Orientations, professional competencies.

Higher Education Academy (HEA). (2007). Retrieved July 10, 2007, from http://www. heacademy.ac.uk/

Higher Education Academy (HEA). (2006). The UK professional standards framework for teaching and supporting learning in higher education. Higher Education Academy. Retrieved March 25, 2008, from http://www.heacademy.ac.uk/ ourwork/policy/framework

Hunt, G., Wright, A., \& Gordon, G. (2007). Evolving expectations for teaching in higher education in Canada. Retrieved July 10, 2007, from http://www.ualberta.ca/ uts/STLHE/ en/handout.html

National Board for Professional Teaching Standards. (2008). Retrieved May 9, 2008, from http:// www.nbpts.org/

Ontario Council of Academic Vice Presidents (OCAV). (2007). Guidelines for university undergraduate degree level expectations. Retrieved July 10, 2007, from http://degree-expectations.apps01.yorku.ca/wordpress/

Ontario Council on Graduate Studies (OCGS). (September 2005). Report of the working groupon graduate degree expectations. Retrieved July 10, 2007, from http://ocgs.cou.on.ca/bin/ briefsReports.cfm

Rodgers, R. Personal communication, July 9, 2007. 
Staff and Educational Development Association-Professional Development Framework (SEDAPDF). (2005). Retrieved July 10, 2007, from http://www.seda.ac.uk/pdf/index.htm

UK Department for Education and Skills. (2003). The future for higher education. Retrieved April 25, 2008, from http://www.dcsf.gov.uk/hegateway/strategy/hestrategy/ 